\title{
Study of Smartphone Addiction and Its Predictors among Medical College Students in Puducherry, South India
}

\author{
Devi $\mathrm{K}^{1, *}$, Harshini $\mathrm{S}^{2}$, Mageswari $\mathbf{R}^{3}$ \\ ${ }^{1}$ Department of Community Medicine, Indira Gandhi Medical College and Research Institute, Puducherry, India \\ ${ }^{2}$ Indira Gandhi Medical College and Research Institute, Puducherry, India \\ ${ }^{3}$ Department of General Medicine, Mahatma Gandhi Post Graduate Institute of Dental Sciences, Puducherry, India
}

Received November 10, 2021; Revised December 24, 2021; Accepted December 31, 2021

\section{Cite This Paper in the following Citation Styles}

(a): [1] Devi K, Harshini S, Mageswari R, "Study of Smartphone Addiction and Its Predictors among Medical College Students in Puducherry, South India," Universal Journal of Public Health, Vol. 10, No. 1, pp. 70 - 78, 2022. DOI: 10.13189/ujph.2022.100108.

(b): Devi K, Harshini S, Mageswari R (2022). Study of Smartphone Addiction and Its Predictors among Medical College Students in Puducherry, South India. Universal Journal of Public Health, 10(1), 70 - 78. DOI: 10.13189/ujph.2022.100108.

Copyright $\bigcirc 2022$ by authors, all rights reserved. Authors agree that this article remains permanently open access under the terms of the Creative Commons Attribution License 4.0 International License

\begin{abstract}
Smartphones are mobile phones with advanced features over and above those of basic phones. Smart phone addiction has been an emerging problem in modern era. But the existing knowledge about excessive use of smartphone still remains insufficient. The objective was to determine the prevalence of smartphone addiction, its predictors and details on smartphone use among medical college students in Puducherry, South India . A cross sectional study involved 253 second and third year medical college students in a Government medical college in Puducherry, South India was carried out. Data were collected using a validated, pretested, structured, and self-administered questionnaire. Appropriate statistical methods such as descriptive statistics, mean and standard deviation were performed for demographic variables. Logistic regression analysis was done to determine demographic and health-related predictors of smartphone addiction. In this present study, the prevalence of smartphone addiction among medical students was $54.2 \%$. Addiction to smart phone had influenced various effects on health such as physical, psychological and social effects. Independent factors such as usage of smart phone for more than two hours, avoiding daily tasks and duties, not being punctual in day-to-day activities were significantly associated with smart phone addiction. To conclude Smart phone as a self-learning tool is essential. But overuse results in addiction. Increased awareness and standardized
\end{abstract}

measures for identification of smart phone addiction and appropriate intervention for those in need of help might alleviate this problem.

Keywords Smart Phone Addiction, Internet Addiction, Medical Students

\section{Introduction}

Smartphones are mobile phones with advanced features over and above that of basic phones. According to Oxford dictionaries (2016) smart phone is defined as a "mobile phone that performs many of the computer's tasks. It usually has a touch screen interface, internet access and an operating system that can run various downloaded applications" [1].

Education, entertainment and information are few of the versatile mobile applications of smart phones in addition to communication. Therefore they are increasingly desired and have become indispensable in everyday life. They have become an increasingly important component of daily life because of its many advantages [2].

Also, smart phone involves four main criterion: irresistible mobile phone use; behaviours like frequent checking for various applications; tolerance and academic, functional or social withdrawal and impairment [3]. 
WHO defines addiction as, "dependence or continuous use of something for the sake of relief, comfort or stimulation which often causes cravings when it is absent" [4].

In the current modern era, smart phone addiction has been an emerging problem. It appears that many students are tending to be dependent more on their smartphones, which eventually leads to addiction [5]. The physical effects of smart phone use include neck pain, headache, dry eyes, refractive error, sleep disorders, obesity or avoidable accidents [6]. Smart phone overuse adversely affects the health due to over exposure to radio frequency waves, microwave and electromagnetic fields. Overindulgence of smart phone affects the brain's electrical activity, impairs cognitive function, alters sleep pattern and even causes irregularities in heart rate and blood pressure [7].

Youngsters, by using smart phones gained multitasking capacity and expanded social interaction but their learning capability has been significantly impaired. [8-11]. Though poor academic performance is the most worrisome effect of smart phone overuse, it also impairs the quality of life by causing mental stress, depression, reduced sleep time, impaired cognitive function which leads to dissatisfaction with life [12-15]. Younger generation, especially college going students, who are attracted towards exploring new technology are vulnerable for smart phone addiction [16].

Thus, it is essential to recognize students who are more likely to develop smartphone addiction. However, meagre knowledge is available about predictors of excessive smartphone use. This study provides insights into smartphone use and its addiction, its predictors among young medical students. With this background, the objectives of this study was to determine the prevalence of smart phone addiction and to identify the various factors associated with smartphone addiction among medical college students in Puducherry, South India.

\section{Material and Methods}

A descriptive cross sectional study involving undergraduate medical students in a Government medical college in Puducherry, South India. The study period was three months from July 2017 - September 2017. Second and third year medical college students having a smart phone and who were willing to participate and gave consent were included in the study.

The sample size was 250 calculated using the formula $\mathrm{n}=4 \mathrm{pq} / \mathrm{d}^{2}$ taking the prevalence of $17 \%$ for smart phone addiction among college students, according to a previous study [17] at 95\% confidence interval and a sample error of $5 \%$ and drop-out rate as $10 \%$. A validated pretested structured self-administered questionnaire which included socio-demographic variables, Smartphone Addiction Scale (SAS) and effects on health among smartphone users was used to collect the data.

Smartphone addiction was assessed using a pre-designed and pre-tested questionnaire designed on the lines of one developed by the Smart phone Addiction Scale (SAS) [18]. The questionnaire was modified according to the local conditions and settings. The Smart phone Addiction Scale (SAS) covers five areas namely, disturbance in daily life, withdrawal, cyberspace-oriented relationship, overuse and tolerance. The results of the SAS analysis showed a Cronbach's alpha of 0.967. Based on the cut-off values, SAS was considered appropriate for the assessment of smartphone addiction.

Further, questionnaire on effects of health among smartphone users include physical, psychological and social effects of health. The Institute Research Committee and Institute Ethics Committee approval was obtained. Written informed consent was obtained and confidentiality was ensured.

Data entry and analysis were done using MS Excel 2010 and SPSS Version 23 (SPSS, Chicago, IL) software respectively. Descriptive statistics, frequency, mean and standard deviation were estimated for demographic characteristics as appropriate. Chi-square test was used to find the association between attributes. A logistic regression analysis was done for determining demographic and health-related predictors of smartphone addiction.

\section{Results}

The study comprised 253 medical college students who were studying MBBS course and their mean age was $20.02 \pm 1.07$ years. Among the total participants $142(56.10 \%)$ of medical students belonged to $3^{\text {rd }}$ year and the rest $111(43.9 \%)$ were studying $2^{\text {nd }}$ year MBBS. Out of the 253 students, males represented $151(59.70 \%)$ and the remaining $102(40.30 \%)$ were females. The mean family income among the medical students studied was $544 \mathrm{U}$. S dollars. Out of the total 253 students surveyed, only $6(2.40 \%)$ and $5(2 \%)$ students were alcoholics and smokers respectively.

The occupation of fathers and mothers of medical students studied was based on classification by the Labour Bureau, Government of India [19]. A majority (69.2\%) of them belonged to semiskilled workers like clerks, typists or drivers, $42(16.6 \%)$ were professionals and 33(13\%) of them were unskilled workers.

Similarly, a majority (94.9\%) of mothers belonged to the semiskilled category. Only $10(4 \%)$ of mothers were professionals and the remaining $1.2 \%$ were unskilled workers.

All 253(100\%) of the medical students under the study owned a smart phone.

Table 1 shows that the overall prevalence of smart phone addiction among medical students. We used a standardized validated smart phone addiction scale to evaluate smart phone addiction. The total scoring was given and an average score above $50 \%$ was considered as smart phone addiction. According to this, the prevalence of smart phone addiction among students studying in medical college was found to be $54.2 \%(137 / 253)$. 
Table 1. Prevalence of smart phone addiction among the medical students

\begin{tabular}{|c|c|c|c|}
\hline S.no & Variables & Number & Percentages \\
\hline 1 & $\begin{array}{c}\text { Smart phone addiction } \\
\text { present }\end{array}$ & $\mathbf{1 3 7}$ & $\mathbf{5 4 . 2 \%}$ \\
\hline 2 & $\begin{array}{c}\text { Smart phone addiction } \\
\text { absent }\end{array}$ & 116 & $45.8 \%$ \\
\hline 3 & Total & 253 & $100 \%$ \\
\hline
\end{tabular}

It was observed that $206(81.40 \%)$ used smart phone for more than 2 hours. 123(48.6\%) of them charged their smart phones once a day. About 91(36\%) charged their phone two times a day and the remaining $39(15.4 \%)$ charged more than two times a day. Data usage was observed to be more than $2 \mathrm{~GB}$ per month in $105(41.5 \%)$ of medical students.

Table 2 gives the purpose of smart phone used by the medical students. A majority (58.9\%) used smart phones for social media, surfing, games and camera. $9.5 \%$ of the participants used smart phones only for communicating in social media. An equal proportion (9.5\%) of them used it for social media and surfing. Another 24(9.5\%) used smart phone for social media, surfing and camera. About $4.4 \%$ of them used it for social media and playing games. $2 \%$ of medical students used it only for surfing.

Table 2. Purpose of smart phone use among the medical college students

\begin{tabular}{|c|c|c|c|}
\hline S.no & Purpose of smart phone use & $\mathbf{N}^{*}$ & Percentages \\
\hline 1 & $\begin{array}{c}\text { Social media, surfing, games, } \\
\text { camera }\end{array}$ & 149 & $58.9 \%$ \\
\hline 2 & Social media, surfing & 24 & $9.5 \%$ \\
\hline 3 & Social media & 24 & $9.5 \%$ \\
\hline 4 & Social media, surfing, camera & 24 & $9.5 \%$ \\
\hline 5 & Social media, surfing, games & 11 & $4.4 \%$ \\
\hline 6 & Social media, games & 10 & $3.9 \%$ \\
\hline 7 & Surfing & 5 & $2 \%$ \\
\hline 8 & Others & 8 & $3.1 \%$ \\
\hline
\end{tabular}

*Multiple responses $(\mathrm{N}=255)$

Table 3. Chi square analysis to find predictors of smartphone addiction among students

\begin{tabular}{|c|c|c|c|c|c|c|c|}
\hline \multirow[b]{2}{*}{$\begin{array}{l}\text { S. } \\
\text { no }\end{array}$} & \multirow[b]{2}{*}{ Variables } & \multirow[b]{2}{*}{$\begin{array}{c}\text { Sub } \\
\text { category }\end{array}$} & \multirow[b]{2}{*}{$\begin{array}{c}\text { Smartphone } \\
\text { Addiction present N(\%) }\end{array}$} & \multirow{2}{*}{$\begin{array}{c}\text { Smartphone } \\
\text { addiction absent } \\
\mathrm{N}(\%)\end{array}$} & \multirow[b]{2}{*}{ Total } & \multicolumn{2}{|c|}{ Chi-square test } \\
\hline & & & & & & $\begin{array}{c}\text { Chi-square } \\
\text { value }\end{array}$ & p-value \\
\hline \multirow{2}{*}{1} & \multirow{2}{*}{ Year } & $2^{\text {nd }}$ year & $51(45.95 \%)$ & $60(54.05 \%)$ & 111 & \multirow{2}{*}{5.36} & \multirow{2}{*}{$0.02 *$} \\
\hline & & $3^{\text {rd }}$ year & $86(60.57 \%)$ & $56(39.34 \%)$ & 142 & & \\
\hline \multirow{2}{*}{2} & \multirow{2}{*}{$\begin{array}{l}\text { Duration of smart } \\
\text { phone use }\end{array}$} & $\leq 2$ hours & $11(23.40 \%)$ & $36(76.60 \%))$ & 47 & \multirow{2}{*}{21.98} & \multirow{2}{*}{$0.00^{*}$} \\
\hline & & $>2$ hours & $126(61.17 \%)$ & $80(38.83 \%)$ & 206 & & \\
\hline \multirow{2}{*}{3} & \multirow{2}{*}{ Eye problems } & Present & $58(72.5 \%)$ & $22(27.5 \%)$ & 80 & \multirow{2}{*}{15.87} & \multirow{2}{*}{$0.00^{*}$} \\
\hline & & Absent & $79(45.67 \%)$ & $94(54.33 \%)$ & 173 & & \\
\hline \multirow{2}{*}{4} & \multirow{2}{*}{$\begin{array}{c}\text { Decreased } \\
\text { physical activity }\end{array}$} & Present & $107(65.24 \%)$ & $57(34.76 \%)$ & 164 & \multirow{2}{*}{23.11} & \multirow{2}{*}{$0.00^{*}$} \\
\hline & & Absent & $30(33.71 \%)$ & $59(66.29 \%)$ & 89 & & \\
\hline \multirow{2}{*}{5} & \multirow{2}{*}{ Headache } & Present & $54(72.97 \%)$ & $20(27.03 \%)$ & 74 & \multirow{2}{*}{14.93} & \multirow{2}{*}{$0.00^{*}$} \\
\hline & & Absent & $83(46.37)$ & $96(53.63 \%)$ & 179 & & \\
\hline 6 & Neck nain & Present & $42(65.62 \%)$ & $22(34.38 \%)$ & 64 & 454 & $003 *$ \\
\hline 6 & Neck pain & Absent & $95(50.26 \%)$ & $94(49.74 \%)$ & 189 & 4.54 & $0.03^{*}$ \\
\hline & & Present & $52(0.65 \%)$ & $28(0.35 \%)$ & 80 & & \\
\hline 7 & Strains & Absent & $85(49.13 \%)$ & $88(50.87 \%)$ & 173 & 5.55 & $0.01^{*}$ \\
\hline 8 & Sleen disturbances & Present & $78(72.22 \%)$ & $30(27.78 \%)$ & 108 & 2470 & $000 *$ \\
\hline 8 & Sieep disturoances & Absent & $59(40.69 \%)$ & $86(59.31 \%)$ & 145 & 24.19 & $0.00^{\circ}$ \\
\hline 0 & & Present & $61(69.32 \%)$ & $27(30.68 \%)$ & 88 & 1250 & $000 *$ \\
\hline 9 & Hear ringtone & Absent & $76(46.06 \%)$ & $89(53.94 \%)$ & 165 & 12.50 & $0.00^{2}$ \\
\hline & & Present & $84(65.12 \%)$ & $45(34.88 \%)$ & 129 & & \\
\hline 10 & Anger and restless & Absent & $53(42.74 \%)$ & $71(57.26 \%)$ & 124 & 12.75 & $0.00^{*}$ \\
\hline & & Present & $95(70.89 \%)$ & $39(29.11 \%)$ & 134 & 3218 & \\
\hline 11 & Lack motivation & Absent & $42(35.29 \%)$ & $77(64.71 \%)$ & 119 & 32.18 & $0.00^{2}$ \\
\hline 12 & & Present & $97(71.85 \%)$ & $38(28.15 \%)$ & 135 & 36.53 & $000 *$ \\
\hline 12 & communication & Absent & $40(33.90 \%)$ & $78(66.10 \%)$ & 118 & 36.53 & $0.00^{2}$ \\
\hline 13 & Ouarrels & Present & $56(66.67 \%)$ & $28(33.33 \%)$ & 84 & 794 & $000 *$ \\
\hline 13 & Quarrels & Absent & $81(47.93 \%)$ & $88(52.07 \%)$ & 169 & 1.94 & $0.00^{2}$ \\
\hline & & Present & $89(77.39 \%)$ & $26(22.61 \%)$ & 115 & & \\
\hline 14 & Avold tasks & Absent & $48(34.78 \%)$ & $90(65.22 \%)$ & 138 & 45.87 & $0.00^{*}$ \\
\hline 15 & Don't feel lonely & Present & $89(61.38 \%)$ & $56(38.62 \%)$ & 145 & 715 & $000 *$ \\
\hline 15 & Don t reer ronery & Absent & $48(44.44 \%)$ & $60(55.56 \%)$ & 108 & 1.15 & $0.00^{6}$ \\
\hline & & Present & $64(81.01 \%)$ & $15(18.99 \%)$ & 79 & & \\
\hline 16 & Not punctual & Absent & $73(41.95 \%)$ & $101(58.05 \%)$ & 174 & 33.39 & $0.00^{2}$ \\
\hline 17 & Responding to & Present & $63(63.64 \%)$ & $36(36.36 \%)$ & 99 & 580 & $001 *$ \\
\hline 17 & people & Absent & $74(48.05 \%)$ & $80(51.95 \%)$ & 154 & 3.89 & $0.01^{*}$ \\
\hline
\end{tabular}

${ }^{*}$ p value $<0.05$ is significant 
Table 3 shows the chi-square analysis to find the predictors of smart phone addiction among medical undergraduate students using a smart phone. From the socio-demographic variables, it was found that smart phone addiction was more among third year students compared to second years $\left(\mathrm{X}^{2}=5.36 ; \mathrm{p}=0.02\right)$. Medical college students who used the smart phone for more than 2 hours $(61.17 \%)$ were significantly associated with smart phone addiction compared to $38.8 \%$ of remaining participants who used the smart phone for less than 2 hours $\left(\mathrm{X}^{2}=21.97 ; \mathrm{p}<0.05\right)$. Eye problems were more common among smart phone addictors $(72.5 \%)$ as compared to students without addiction $(27.5 \%)$ and was found to be statistically significant $\left(X^{2}=15.86 ; p<0.05\right)$. Headache was higher $(72.97 \%)$ among participants with smart phone addiction compared to $27.03 \%$ of them without addiction. This difference was statistically significant $\left(\mathrm{X}^{2}=14.92 ; \mathrm{p}<\right.$ $0.05) .65 .62 \%$ of medical students with smart phone addiction complained of neck pain compared to those without addiction $(34.38 \%)$. This difference was statistically significant $(p<0.05)$. Also, the proportion of students who reported strains was significantly higher among those with smart phone addiction as compared to the ones without addiction ( $65 \%$ vs $35 \%$ ). About $72.2 \%$ of participants with smart phone addiction complained of sleep disturbances compared to $27.78 \%$ without smart phone addiction. This difference was statistically significant $\left(X^{2}=24.78 ; p<0.05\right) .69 .32 \%$ of medical students with smart phone addiction complained of hearing ringtones in its absence, which was significantly higher among students without addiction (30.68\%). The proportion of medical students with smart phone addiction who reported anger, irritability and restlessness during unreachable network was significantly higher compared to students without addiction (65.12\% vs $34.88 \%)$. Lack of motivation in studies was significantly higher among smart phone addictors $(70.89 \%)$ compared to $29.11 \%$ without smart phone addiction. This difference was statistically significant $\left(\mathrm{X}^{2}=32.17 ; \mathrm{p}<0.05\right)$. Looking at the social factors, the proportion of medical students with poor communication was significantly higher among the ones with smart phone addiction (71.85\%) compared to those without addiction (28.15\%). This difference was significant $\left(X^{2}=36.53 ; p<0.05\right)$. Quarrelling with siblings was significantly higher among students with smart phone addiction ( $66.67 \%$ ) compared to $33.33 \%$ without smart phone addiction. $77.39 \%$ of medical students with smart phone addiction avoided daily tasks and duties compared to $22.61 \%$ without addiction. This difference was statistically significant $\left(X^{2}=45.86 \% ; p<0.05\right)$. Among the smart phone addictors, students who don't feel lonely when using the smart phone were significantly higher $(61.38 \%)$ compared to ones without addiction (38.62\%). It was observed that $81 \%$ of students with smart phone addiction reported as not being punctual in daily activities as compared to $18.99 \%$ without addiction. This difference was statistically significant $(\mathrm{p}<0.05)$. Medical students with smart phone addiction who don't mind responding to people were $63.64 \%$ compared to students without addiction. This difference was also statistically significant $(p<0.05)$.

Table 4 gives the univariate analysis of the significant risk factors for smart phone addiction among medical college students. According to the Univariate logistic regression model, the factors associated significantly with use of smart phone was the duration of smart phone use, eye problems, decreased physical activity, headache, neck pain, strains, sleep disturbances, hearing the ringtone, anger, irritable and restless, lack of motivation to study, poor communication, quarrels, avoiding daily tasks, feels lonely, not punctual and responding while using smart phone. These significant risk factors were fitted in the logistic regression model to see the independent effect by controlling the confounders. 
Table 4. Univariate analysis of risk factors of smartphone addiction among respondents

\begin{tabular}{|c|c|c|c|c|c|c|}
\hline $\begin{array}{l}\text { S. } \\
\text { no }\end{array}$ & Variables & Responses & $\begin{array}{c}\text { Smart phone } \\
\text { addiction present }\end{array}$ & $\begin{array}{c}\text { Smartphone } \\
\text { addiction Absent }\end{array}$ & Sig & $\begin{array}{c}\text { OR } \\
(95 \% \mathrm{CI})\end{array}$ \\
\hline \multirow{2}{*}{1} & \multirow{2}{*}{ Year } & $2^{\text {nd }}$ year & 51 & 60 & \multirow{2}{*}{$0.02 *$} & \multirow{2}{*}{$\begin{array}{c}1.80 \\
(1.09-2.98)\end{array}$} \\
\hline & & $3^{\text {rd }}$ year & 86 & 56 & & \\
\hline \multirow{2}{*}{2} & \multirow{2}{*}{$\begin{array}{c}\text { Duration of smart phone } \\
\text { use }\end{array}$} & $\leq 2$ hours & 11 & 36 & \multirow{2}{*}{$0.00 *$} & \multirow{2}{*}{$\begin{array}{c}5.15 \\
(2.48-10.70)\end{array}$} \\
\hline & & $>2$ hours & 126 & 80 & & \\
\hline \multirow{2}{*}{3} & \multirow{2}{*}{ Eye problems } & Present & 58 & 22 & \multirow{2}{*}{$0.00 *$} & \multirow{2}{*}{$\begin{array}{c}3.14 \\
(1.77-5.57)\end{array}$} \\
\hline & & Absent & 79 & 94 & & \\
\hline \multirow{2}{*}{4} & \multirow{2}{*}{ Decreased physical activity } & Present & 107 & 57 & \multirow{2}{*}{$0.00 *$} & \multirow{2}{*}{$\begin{array}{c}3.69 \\
(2.14-6.36)\end{array}$} \\
\hline & & Absent & 30 & 59 & & \\
\hline \multirow{2}{*}{5} & \multirow{2}{*}{ Headache } & Present & 54 & 20 & \multirow{2}{*}{$0.00 *$} & \multirow{2}{*}{$\begin{array}{c}3.12 \\
(1.73-5.64)\end{array}$} \\
\hline & & Absent & 83 & 96 & & \\
\hline \multirow{2}{*}{6} & \multirow{2}{*}{ Neck pain } & Present & 42 & 22 & \multirow{2}{*}{$0.00 *$} & \multirow{2}{*}{$\begin{array}{c}1.89 \\
(1.05-3.41)\end{array}$} \\
\hline & & Absent & 95 & 94 & & \\
\hline \multirow{2}{*}{7} & \multirow{2}{*}{ Strains } & Present & 52 & 28 & \multirow{2}{*}{$0.01 *$} & \multirow{2}{*}{$\begin{array}{c}1.92 \\
(1.11-3.33)\end{array}$} \\
\hline & & Absent & 85 & 88 & & \\
\hline 8 & Sleen disturbances & Present & 78 & 30 & $000 *$ & 3.79 \\
\hline 0 & sieep aisturoances & Absent & 59 & 86 & 0.00 & $(2.22-6.48)$ \\
\hline 0 & Hear ringtone & Present & 61 & 27 & $000 *$ & 2.65 \\
\hline 9 & Hedil mingionte & Absent & 76 & 89 & 0.00 & $(1.53-4.57)$ \\
\hline 10 & Anger and rectlecs & Present & 84 & 45 & $000 *$ & 2.50 \\
\hline 10 & Anger allu restress & Absent & 53 & 71 & 0.00 & $(1.51-4.15)$ \\
\hline 11 & I ack motivation & Present & 95 & 39 & $000 *$ & 4.47 \\
\hline 11 & Lack motivation & Absent & 42 & 77 & 0.00 & $(2.63-7.58)$ \\
\hline 12 & Poor communication & Present & 97 & 38 & $000 *$ & 4.98 \\
\hline 12 & 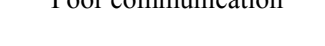 & Absent & 40 & 78 & 0.00 & $(2.92-8.49)$ \\
\hline 13 & Ouarrels & Present & 56 & 28 & $000 *$ & 2.17 \\
\hline 15 & Quarters & Absent & 81 & 88 & 0.00 & $(1.26-3.75)$ \\
\hline 14 & A void tockse & Present & 89 & 26 & $000 *$ & 6.42 \\
\hline 14 & Avord tasks & Absent & 48 & 90 & $0.00^{\circ}$ & $(3.67-11.24)$ \\
\hline 15 & I pnoly & Present & 89 & 56 & $000 *$ & 1.99 \\
\hline 15 & Lomery & Absent & 48 & 60 & $0.00^{\circ}$ & $(1.19-3.29)$ \\
\hline 16 & Dunctual & Present & 64 & 15 & $000 *$ & 5.90 \\
\hline 10 & Punctual & Absent & 73 & 101 & $0.00^{\circ}$ & $(3.12-11.17)$ \\
\hline 17 & Pesnonse & Present & 63 & 36 & $001 *$ & 1.89 \\
\hline 17 & Kesponse & Absent & 74 & 80 & $0.01^{\circ}$ & $(1.13-3.17)$ \\
\hline
\end{tabular}

${ }^{*}$ p value $<0.05$ was considered significant 
Table 5. Logistic regression model of predictors of smart phone addiction

\begin{tabular}{|c|c|c|c|c|c|c|c|c|}
\hline S.no & Variables & B & SE & Wald & df & Sig & Exp(B) & 95\% CI \\
\hline 1 & Year & 0.37 & 0.32 & 1.32 & 1 & 0.24 & 1.45 & $0.76-2.77$ \\
\hline 2 & Duration of smart phone use & 1.08 & 0.45 & 5.54 & 1 & $0.01 *$ & 2.94 & $1.19-7.25$ \\
\hline 3 & Eye problems & 0.64 & 0.38 & 2.87 & 1 & 0.09 & 1.90 & $0.90-4.02$ \\
\hline 4 & Decreased physical activity & 0.32 & 0.39 & 0.66 & 1 & 0.41 & 1.37 & $0.64-2.96$ \\
\hline 5 & Headache & 0.30 & 0.40 & 0.55 & 1 & 0.45 & 1.35 & $0.61-2.99$ \\
\hline 6 & Neck pain & -0.25 & 0.41 & 0.38 & 1 & 0.53 & 0.77 & $0.34-1.74$ \\
\hline 7 & Strains & 0.35 & 0.38 & 0.84 & 1 & 0.35 & 1.42 & $0.66-3.06$ \\
\hline 8 & Sleep disturbances & 0.34 & 0.35 & 0.93 & 1 & 0.33 & 1.41 & $0.70-2.84$ \\
\hline 9 & Hear ringtone & 0.57 & 0.35 & 2.62 & 1 & 0.10 & 1.77 & $0.88-3.56$ \\
\hline 10 & Anger and restless & 0.52 & 0.34 & 2.26 & 1 & 0.13 & 1.67 & $0.85-3.29$ \\
\hline 11 & Lack motivation & 0.46 & 0.34 & 1.79 & 1 & 0.18 & 1.59 & $0.80-3.14$ \\
\hline 12 & Poor communication & 0.55 & 0.36 & 2.24 & 1 & 0.13 & 1.72 & $0.84-3.53$ \\
\hline 13 & Quarrels & 0.08 & 0.35 & 0.06 & 1 & 0.80 & 1.09 & $0.54-2.19$ \\
\hline 14 & Avoid tasks & 0.93 & 0.37 & 6.28 & 1 & $0.01 *$ & 2.55 & $1.22-5.30$ \\
\hline 15 & Lonely & 0.17 & 0.34 & 0.26 & 1 & 0.61 & 1.19 & $0.60-2.36$ \\
\hline 16 & Not Punctual & 0.79 & 0.39 & 3.98 & 1 & $0.04 *$ & 2.21 & $1.01-4.83$ \\
\hline 17 & Response & -0.07 & 0.35 & 0.04 & 1 & 0.83 & 0.92 & $0.46-1.85$ \\
\hline & Constant & -3.31 & 0.57 & 33.51 & 1 & 0.00 & 0.03 & \\
\hline
\end{tabular}

Table 5 shows the logistic regression model of risk factors for smart phone addiction among medical students. Duration of smart phone use, avoiding daily tasks and duties and not being punctual in daily activities was found to be significantly associated with the smart phone addiction. Medical students who use smart phone for more than 2 hours were at a higher risk of developing smart phone addiction $(\mathrm{OR}=2.94,95 \% \mathrm{CI}=1.19-7.25)$ compared to students who use them for a shorter duration (less than or equal to 2 hours). Medical students who avoid daily tasks and duties had 2.55 times the risk of developing smart phone addiction $(\mathrm{OR}=2.55,95 \% \mathrm{CI}=1.22-5.30)$. Not being punctual in day to day activities had a higher risk of developing smart phone addiction $(\mathrm{OR}=1.69,95 \% \mathrm{CI}=$ $1.07-2.69)$.

\section{Discussion}

The purpose of this study was to determine the prevalence of smartphone addiction and to identify the various factors related to smartphone use. It was decided to conduct the study among young adults as they remain the target group of consumers for smartphone use. Smart phones are becoming almost inevitable in everyday life for most of the medical graduates, thereby increasing the risk of addiction during their adolescent or early adulthood period. Hence, this study was conducted among 253 undergraduate medical students in a Government medical college located at Puducherry, South India.

The prevalence of smart phone addiction was evaluated using a standardized, pretested and validated Smart phone Addiction Scale (SAS) [18]. The prevalence of smartphone addiction quantified in this study was found to be $54.2 \%$ (137/253). This finding was similar to the study done among medical college students in Mansoura where the prevalence was $53.6 \%$ [20]. Similar findings were reported in the studies conducted by Dhamija S et al [21] in Maharashtra and by Awasthi S et al [22] in Uttarakhand. A study on nomophobic behaviours among smartphone users in West Bengal reported that the proportion of smart phone addiction among medical students was 42.6\% [23]. Smart phone addiction among medical students in China was $39.7 \%$ [24]. Similarly, smartphone addiction was found $36.8 \%$ among medical students in Nepal [25]. A higher prevalence of $85.4 \%$ was reported in the study done by Sethuraman AR et al [26] in Andaman and by Okasha T et al in Egypt [27].

Whereas in a study conducted by the Swiss Research Institute for Public health smartphone addiction was $16.9 \%$ among young people in Switzerland [17]. The prevalence among British adolescents of age 11-14 was 10\% [28]. The prevalence of addiction to internet was $4.9-10.7 \%$ in Korea and is viewed as a serious public health issue [29]. The prevalence of smart phone addiction among medical students in Assam was 28.6\% [30]. In India, addiction is stated at $39-44 \%$ in this age group [31]. High smart phone addiction in the present study could be owing to the lack of other sources of outdoor activities. As medical students are preoccupied with heavy academic syllabus and they use smart phone as the only tool of entertainment to relieve their stress. In addition to that, they may have a constant 
obsession to take selfie and post them on social media which is easily available in smart phone besides various applications of chatting, gaming and social media [26]. The differences in the prevalence among different studies may reflect the differences in methodology, assessment scales used, definitions of smart phone addiction and different population characteristics studied.

In the present study, the mean age of the participants was $20.02 \pm 1.07$. Since the study was conducted among medical undergraduate students similar finding was observed in other studies also [20-22, 24-26]. Compared to older generations, younger generations are more prone towards using smart phones for their fascinating features other than communication, because they are more susceptible to change in fashion trends and styles [32].

The present study showed that out of total smart phone users, $59.7 \%$ were males and $40.3 \%$ were females. This result was consistent with the study done by Liu $\mathrm{H}$ et al [24] where $61.4 \%$ were males and $59.3 \%$ were females. In a study by Bisen et al, it was shown that male students are more inclined to smartphone addiction than female students [33].

In a study population, the mean family income of the parents was 544 U.S dollars. In the study by Ithnain $\mathrm{N}$ et al [34] mean family income was 946.63 U.S. Dollars among medical students.

Out of 253 students studied, $2.4 \%$ and $2 \%$ were alcoholics and smokers respectively. A study conducted in Switzerland revealed that smartphone addiction was not linked to the use of alcohol or tobacco [17]. This result was also consistent with the study done by Kwon and Kim et al that excessive smartphone use is not associated with tobacco or alcohol use [35].

In the present study majority (81.4\%) of students used their smartphone more than 2 hours in a day. This finding was similar to a study by Ghosh P et al [30], Surwase K et al [36] and Krishnamurthy et al [37] where the average use of internet per day was 2-3 hours. However, in another study by Ithnain $\mathrm{N}$ et al [34] in Malaysia reported usage of more than 3 hours per day. Studies done by Lee et al [38] and Lin et al [39] demonstrated that frequent use of smart phone had a stronger association with smartphone addiction than the duration of use.

With regards to the purpose of smart phone use, $58.9 \%$ used it for social media, surfing and camera. $9.5 \%$ of the participants used it only for social media. An equal proportion $(9.5 \%)$ of participants used the smart phone for social media and surfing. Rest of the participants used smart phone for interacting in social media, surfing and for using camera. Another study by Eldesokey S et al [20] observed medical students widely used smart phones for social interaction $(66.8 \%)$, to watch news $(43.7 \%)$, for academic activities $(39.2 \%)$, playing games $(28.5 \%)$, educational $(22.4 \% \%)$ and for scientific purposes $(21 \%)$. Another study by Ithnain $\mathrm{N}$ et al [34] reported smart phones were used for social networking sites $(67 \%)$, calls/ SMS (23.8\%), games/ application (4.4\%) and information/ news (3.5\%).

A similar finding was also observed by Ghosh $\mathrm{P}$ et al [30] where the most familiar functional use of smart phone was social networking $(51.4 \%)$, making phone calls $(21.4 \%)$ followed by gaming $(5.7 \%)$, text messaging $(5.7 \%)$ and listening music by $5.7 \%$ of the medicos.

In the present study, the independent risk factors for smart phone addiction among the medical students were the duration of smart phone use, students who avoid daily tasks and duties and not being punctual in day to day activities were significantly associated with smart phone addiction among medical students. One such study reported that higher proportion of smartphone addiction were associated with females, possessing smartphone for more than 2 years, using it daily for more than 4 hours and paying 2.62 U.S dollars and above as monthly bills [23]. The study conducted by Eldesokey S [20] observed that independent predictors of smart phone addiction were studying less than or equal to 4 hours, mild/ moderate depression, severe/ extreme severe depression and severe/ extreme severe stress. Liu $\mathrm{H}$ et al [24] reported four factors i.e., professional identity, poor mental health, smart phone use before bedtime and study pressure were independent risk factors of smart phone addiction among medical students. Another research by Karki S et al [25] reported the prime predictors of smartphone addiction among medical students were male gender, overuse and self-acceptance addiction. The study conducted by Haug $\mathrm{S}$ et al in Switzerland found that smartphone addiction was more prevalent in young adolescents group of 15-16 years of age, students whose parents were both born abroad, those with less physical activity and more stress [17]. Also, a study conducted in Korea revealed that high-risk smartphone users had less physical activity. Moreover, the time of smartphone use was in proportional relationship with smartphone addiction [40].

\section{Conclusion}

In the present study the prevalence of smartphone addiction among medical students was $54.2 \%$. Addiction to smartphone had influenced various effects on health such as physical, psychological and social effects. Independent factors such as usage of smart phone for more than two hours, avoiding daily tasks and duties, not being punctual in day-to-day activities were significantly associated with smart phone addiction.

Smart phones as a self-learning tool are essential. But their benefits lead to excessive use thereby resulting in addiction. Increased awareness is needed among the medical college students regarding smart phone addiction and its effects. 


\section{REFERENCES}

[1] Oxford dictionaries. Smart phones [updated 2016; cited 2015 sep 2016]. Available from http://www.Oxforddiction aries.com/definition/english/smartphone

[2] Alosaimi F. D., Alyahya H., Alshahwan H., Al Mahyijari N., Shaik S. A, "Smartphone addiction among university students in Riyadh, Saudi Arabia," Saudi Med J, vol. 37, no. 6, pp. 675-83, 2016. DOI: 10.15537/Smj.2016.6.14430.

[3] Lin Y. H., Chiang C. L., Lin P. H., Chang L. R., Ko C. H., Lee Y. H., Lin S. H, "Proposed Diagnostic Criteria for Smartphone Addiction," PLoS One, vol. 11, no. 11, e0163010, 2016. DOI: 10.1371/journal.pone.0163010.

[4] WHO, "Management of substance abuse: Dependence Syndrome," http://www.who.int/substance abuse/terminol ogy/definition1/en (Accessed Mar. 26, 2014)

[5] Lee S., Kang H., Shin G, "Head flexion angle while using a smartphone," Ergonomics, vol. 58, no. 2, pp. 220-226, 2015. http://dx.doi.org/10.1080/00140139.2014.967311

[6] Klauer S. G., Guo F., Morton S. B. G., Ouimet M. C., Lee S., Dingus T. A, "Distracted driving and risk of road crashes among novice and experienced drivers," The New England Journal of Medicine, vol. 370, no. 1, pp. 54-59, 2014. DOI: 10.1056/NEJMsa1204142

[7] WHO, "Electromagnetic fields and public health: mobile phones." http://www.who.int/mediacentre/factsheets/fs193 /en/. 2014 (Accessed on Oct. 8, 2014)

[8] Rotondi V., Stanca L., Tomasuolo M, "Connecting alone: Smartphone use, quality of social interactions and well-being?" J Econ Psychol, vol. 63, pp. 17-26, 2017. DOI: 10.1016/j.joep. 2017.09.001.

[9] Gladden D, "The effects of smartphones on social lives: How they affect our social interactions and attitudes2018 OTS Master's Level Projects \& Papers 586. Available from: https://digitalcommonsoduedu/ots_masters_projects/586.

[10] Carrillo R., Subrahmanyam K, Mobile phone multitasking and learning. Available from: https://wwwsemanticscholar org/paper/Mobile-Phone-Multitasking-and-Learning-Carril lo-Subrahmanyam/587c01633ea2458f5e509fffcead32c008 fedf66\#citing-papers. DOI: 104018/978-1-4666-8239-9ch0 07.

[11] Chen Q., Yan Z, "Does multitasking with mobile phones affect learning?? A review," Comput Hum Behav, vol. 54, pp. 34-42, 2016. DOI: 10.1016/j.chb. 2015.07.047.

[12] Wallace P, "Internet addiction disorder and youth," EMBO Rep, vol. 15, no. 1, pp. 12-16, 2014. DOI: 101002/embr201338222.

[13] Samaha M., Hawi N. S, "Relationships among smartphone addiction, stress, academic performance, and satisfaction with life," Comput Hum Behav, vol. 57, pp. 321-5, 2016. DOI: $10.1016 /$ j.chb.2015.12.045

[14] Tao S., Wu X., Zhang S., Tong S., Hao J., Tao F, "Association of alcohol use with problematic mobile phone use and depressive symptoms among college students in Anhui, China," J Public Health, vol. 25, no. 1, pp. 103-12, 2017. DOI: https://doi.org/10.1007/s10389-016-0766-z

[15] Ward A. F., Duke K., Gneezy A., Bos M. W, "Brain drain:
The mere presence of one's own smartphone reduces available cognitive capacity," J Assoc Consum Res, vol. 2, no. 2, pp. 140-54, 2017. DOI: http://dx.doi.org/10.1086/69 1462.

[16] Awasthi S., Kaur A., Solanki H. K., Pamei G., Bhatt M, "Smartphone use and the quality of life of medical students in the Kumaun Region, Uttarakhand," J Family Med Prim Care, vol. 9, no. 8, pp. 4252-4258, 2020. DOI: $10.4103 /$ jfmpc.jfmpc_805_20.

[17] Haug S., Castro R. P., Kwon M., Filler A., Kowatsch T., Schaub M. P, "Smartphone use and smartphone addiction among young people in Switzerland," Journal of Behavioral Addictions, vol. 4, no. 4, pp. 299-307, 2015. DOI: $10.1556 / 2006.4 .2015 .037$

[18] Kwon M., Lee J. Y., Won W. Y., Park J. W., Min J. A., Hahn C, "Development and validation of a Smartphone Addiction Scale(SAS)," PloS One, vol. 8, no. 2, pp. 1-7, 2013. https://doi.org/10.1371/journal.pone.0056936.

[19] Labour Bureau, Government of India Report, "One evaluation studies on implementation of Minimun Wages Act, 1948," Annual Report 1999-2000, Ministry of Labour, Government of India, pp. 93. Avialable from http://labourbureau.nic.in/MW3ch5.htm

[20] Eldesokey S., Gomaa Z., Sabri Y., El-Gilany A. H., Elwasify Mohamed, "Smartphone addiction among medical students in mansoura university," Egyptian Journal of Psychiatry, vol. 42, no. 1, pp. 42-50, 2021. DOI: 10.4103/ejpsy.ejpsy_47_20.

[21] Dhamija S., Shailaja B., Chaudhari B., Chaudhury S., Saldanha D, "Prevalence of smartphone addiction and its relation with sleep disturbance and low self- esteem among medical college students," Ind Psychiatry J, vol. 30, no. 1, pp. S189-S194, 2021. DOI: 10.4103/0972-6748.328813.

[22] Awasthi S., Kaur A., Solanki H. K., Pamei G., Bhatt M, "Smartphone use and the quality of life of medical students in the Kumaun Region, Uttarakhand," J Family Med Prim Care, vol. 9, no. 8, pp. 4252-4258, 2020. DOI: 10.4103/jfmpc.jfmpc_805_20

[23] Dasgupta P., Bhattacherjee S., Dasgupta S., Roy J. K., Mukherjee A., Biswas R, "Nomophobic behaviors among smartphone using medical and engineering students in two colleges of West Bengal," Indian Journal of Public Health, vol. 61, no. 3, pp. 199-204, 2017. DOI: 10.4103/ijph.IJPH_81_16

[24] Liu H., Zhang M., Zhou Z., Zhu E., Huang L, "Smartphone Addiction and its Associated Factors Among Freshmen Medical Students in China: A Cross-Sectional Study," Research Square, pp. 1-15, 2021. DOI: 10.21203/rs.3.rs-1071201/v1.

[25] Karki S., Singh J. P., Paudel G., Khatiwada S., Timilsina S, "How addicted are newly admitted undergraduate medical students to smartphones?: a cross-sectional study from Chitwan medical college, Nepal," BMC Psychiatry, vol. 20, no. 1, pp.1-7, 2020. DOI: 10.1186/s12888-020-02507-1

[26] Sethuraman A. R., Rao S., Charlette L., Thatkar P. V., Vincent V, "Smartphone addiction among medical college students in the Andaman and Nicobar Islands," International Journal of Community Medicine and Public Health, vol. 5, no. 10, pp. 4273-4277, 2018. DOI: http://dx.doi.org/10.18203/2394-6040.ijcmph20183867. 
[27] Okasha T., Saad A., Ibrahim I., Elhabiby M., Khalil S., Morsy M, "Prevalence of smartphone addiction and its correlates in a sample of Egyptian university students". Int J Soc Psychiatry, 2021, 207640211042917. DOI: 10.1177/00207640211042917. Epub ahead of print.

[28] Lopez-Fernandez O., Honrubia-Serrano L., Freixa-Blanxart M., Gibson W, "Prevalence of problematic mobile phone use in British adolescents," Cyberpsychology, Behavior, and Social Networking, vol. 17, no. 2, pp. 91-98, 2014. DOI: https://doi.org/10.1089/cyber.2012.0260

[29] Koo H. J., Kwon J. H, "Risk and protective factors of internet addiction: a meta-analysis of empirical studies in Korea," Yonsei Medical Journal, vol. 55, no. 6, pp. 16911711, 2014. DOI: 10.3349/ymj.2014.55.6.1691

[30] Ghosh P., Ghosh A., Khasnabis M, "Prevalence of smart phone addiction: Correlates of smartphone use and its association with social phobia in Post graduate Medical students in Assam," International Journal of Community Medicine and Public Health, vol. 8, no. 4, pp. 1836-1841, 2021. DOI:10.18203/2394-6040.ijcmph20211242

[31] Davey S., Davey A, "Assessment of Smartphone Addiction in Indian Adolescents: A Mixed Method Study by Systematic-review and Meta-analysis Approach," Journal Preventive Medicine, vol. 5, no. 12, pp. 1500-1511, 2014. PMCID: PMC4336980

[32] Goswami V., Singh D. R, "Impact of mobile phone addiction on adolescent's life:A literature review," International Journal of Home Science, vol. 2, no. 1, pp. 69-74, 2016. https://www.homesciencejournal.com

[33] Bisen S., Deshpande Y, "An Analytical Study of Smartphone Addiction among Engineering Students: A Gender Differences," International Journal of Indian Psychology, vol. 4, no. 1, pp. 81, 2016. DIP: $18.01 .128 / 20160401$
[34] Ithnain N., Ghazali S. E., Jaafar N, "Relationship between Smartphone Addiction with Anxiety and Depression among Undergraduate Students in Malaysia," International Journal of Health Science Research, vol. 8, no. 1, pp. 163-171, 2018. DOI: https://www.ijhsr.org/IJHSR Vol.8_Issue.1_Jan2018/IJHSR_Abstract.025.html, 2018

[35] Kwon M., Kim D. J., Cho H., Yang S, "The Smartphone Addiction Scale: Development and Validation of a Short Version for Adolescents," PLoS ONE, vol. 8, no. 12, pp. e83558, 2013.https://doi.org/10.1371/journal.pone.008355 8

[36] Surwase K., Bagdey P., Adikane H, "Prevalence and Associated Risk Factors of Internet Addiction in College Going Students in Nanded city," National Journal of Community Medicine, vol. 8, no. 5, pp. 213-218, 2017.

[37] Krishnamurthy S., Chetlapalli S. K, "Internet addiction: Prevalence and risk factors: A cross-sectional study among college students in Bengaluru, the Silicon Valley of India," Indian Journal of Public Health, vol. 59, no. 2, pp. 115-121, 2015. DOI: 10.4103/0019-557X.157531

[38] Lee H., Ahn H., Choi S., Choi W. J, "The SAMS: Smartphone Addiction Management System and verification," Journal of Medical Systems, vol. 38, no. 1, pp. 1, 2014. DOI: 10.1007/s10916-013-0001-1

[39] Lin Y. H., Lin Y. C., Lee Y. H., Lin P. H., Lin S. H., Chang L. R., Tseng H. W., Yen L. Y., Yang C. C. H., Kuo T. B. J, "Time distortion associated with smartphone addiction: Identifying smartphone addiction via a mobile application (App)," Journal of Psychiatric Research, vol. 65, pp. 139-145, 2015. DOI: 10.1016/j.jpsychires.2015.04.003

[40] Kim S. E., Kim J. W., Jee Y. S, "Relationship between smartphone addiction and physical activity in Chinese international students in Korea," Journal of Behavioral Addictions, vol. 4, no. 3, pp. 200-205, 2015. DOI: $10.1556 / 2006.4 .2015 .028$ 